\title{
Forest management units through cost
}

\author{
Cristina Otilia Tenovici, „Constantin Brancoveanu” University of Rm. Vâlcea, Romania \\ Mihaela Albici, „Constantin Brancoveanu” University of Rm. Vâlcea, Romania
}

\begin{abstract}
Costs minimizing and profit maximizing make the costs adjustment seems to be a vital necessity when the activity developed within the company does not assure the maintenance and stability of the necessary relation between consuming factors and costs. In such circumstances, approaching differing sides of the production cost and improving the methods of calculation has much significance in determining the most appropriate measures necessary for its adjustment and for profit increasing. The whole informational process of costs - formation, control and analysis of costs - involves a careful use the methodological concepts known under the name of classical methods and modern or complementary methods, as well as of other proceedings. Such methods and proceedings cannot be applied separately, only conjugated and integrated in a unitary methodological system, each of these methods and proceedings participating at achieving one or more objectives. Only by their unitary action they can fulfill all the system objective
\end{abstract}

\section{Keywords}

Cost, economic efficiency, decisions substantiation, traditional and modern methods for costs determining.

\section{JEL Codes: M 41, Q 00}

The future managers will not be able to perform without data provided by management accounting and they have to get used to the proper terminology, its techniques and the way in which the supplied data can be used, as well as the possible limits of this information. The forestry unit has to make up and to use a system of knowing products, working and services costs so that it can be able to set the sales price according to the market demands and the expected margins ${ }^{1}$.

Costs determination and their evolution for the products specific to forestry units does not represent a purpose but it is due, on the one hand, to managers orientation changes, who are forced to use a certain tool capable to make possible an intervention for prices adjustment. Consequently they ask for competent, relevant and appropriate accounting information on costs. On the other hand, maintaining the forestry unit economic efficiency in the present conditions of technological improvement acceleration and competition intensification which involves competitiveness (private floristries) depends on the manager's possibility of knowing costs and consequently, performing, through appropriate decisions.

The process of decision making involves cost. It influences the decision process in many ways: the relation costs-prices; relation costs-profit; relation costs- economic efficiency. These relations do not represent something new, as they have been present in traditional economic literature. Only it is necessary to rearrange them on according to new principles, taking into consideration the market economy demands and fundamentals. Thus, in the

\footnotetext{
${ }^{1}$ Tenovici C.O. (2007) Projecting the informatic system of cost determination and analisys in forestry, Universitaria Publishing House, Craiova, p.12
} 


\section{Studies and Scientific Researches - Economic Edition, no. 15, 2010}

countries with planned economy they have paid more attention to costs than to prices, considering it to be a direct relation, prices being established according to costs, in the market economy the relation between cost and price becomes a dominant feature.

The costs influences directly the price formed on the market, by means of the cost included in the product offer price. In addition, the market price has an indirect role on costs, forcing producers to reduce costs for increasing profit, the producers with reduced costs having more advantage.

The changing perspective on the relation between cost and profit had determined important changes in costs determining process, analysis and control, turning it into a permanent activity of operational checking each and every operation that generates expenses included in cost, in order to find out the ways and means of reducing them ${ }^{2}$.

Top level management has in view costs minimizing, so profit maximizing, so that costs adjustment seems to be a vital necessity when the activity developed within the company does not assure the maintenance and stability of the necessary relation between consuming factors and costs. Costs level and their structure reflects the forestry unit managers' concern with practicing the new technique, with an efficient using of production factors, their approach on productive activity organizing and managing process, the substantiation level of decisions. In such circumstances, approaching differing sides of the production cost and improving the methods of calculation has much significance in determining the most appropriate measures necessary for its adjustment and for profit increasing.

The whole informational process of costs - formation, control and analysis of costs involves a careful use the methodological concepts known under the name of classical methods and modern or complementary methods, as well as of other proceedings such as: supplement process, simple division process, process of equivalent coefficients, etc. Such methods and proceedings cannot be applied separately, only conjugated and integrated in a unitary methodological system, each of these methods and proceedings participating at achieving one or more objectives. Only by their unitary action they can fulfil all the system objectives.

Perfecting the costs informational system by means of automatic data processing should be preceded by the existent costs informational system reorganization. If this aspect is neglected the success and the efficiency of system improvement is harder to be achieved, as the new system will be based on weak system, which still contains many flaws resulted from data manual processing. It is recommended the integrated reorganization by means of models established beforehand that unify in a unitary conception all methods, procedures, the forms of data gathering, processing, valorisation and storing.

Reconsidering management accountability and costs calculation is one of the main factors of efficient organization of economic activity. It should become able to supply information that meets the requirements of the forestry activity efficient management in the present market economy. The information about production costs occupies a central position, determined by their implications on the actual state and on the future evolution of the unit activity. Thus, an efficient leadership on the forestry unit level cannot be undertaken without an informational system able to meet the requirements of a modern production management that allows taking operative decisions and measures, thoroughly founded and on the right time ${ }^{3}$.

The traditional methods of cost determining, including the global method used in forestry for determining and calculating costs, cannot meet the present requirements that aim at performing a modern management which involves adapting and perfecting such methods.

A first drawback of these classical (traditional) methods is the great labour volume, as they involve performing two series of calculations on the production cost: provisional calculation

\footnotetext{
${ }^{2}$ Baciu T.A. (2001), Costs - organization, planning, accounting, calculation, control and analysis, Dacia Publishing House, Cluj- Napoca, p. 34

${ }^{3}$ Tenovici C.O. (2007) Projecting the informatic system of cost determination and analisys in forestry, Universitaria Publishing House, Craiova, p.20
} 
and historical costing. Provisional calculations are done before the productive process beginning through budget processing and the production expenses on the forestry unit level as well as the wood mass cost budget, according to the wood mass spore supposed to be gained according to the regulations in force and the consumption laws established. They also involve the exploitation budget for plots that are to be exploited on the forestry unit level as well as the budget of the unitary cost for each type of wood mass processed. Budget processing starts from the integral achievement of works and assignments stipulated in the regulations.

Historical costing is done after finishing the productive process. In forestry, as we have mentioned before, the productive process takes place over one year and it involves all measures taken for treating the trees necessary for obtaining wood mass spore, according to regulations. Such calculations are to be done at the end of each month, called partial historical costing, using the global accumulated calculation.

Even if the effective cost is more likely to be precise and more detailed, these aspects cannot make for the delay with which it is obtained, since modern leadership asks for proper and pertinent data, instead of the exact ones but obtained too late ${ }^{4}$.

Traditional calculation methods, that are the global method used in forestry, allow the regular determination of cost, but only at the end of the production cycle. Consequently, the information supplied by means of such classical methods has a historical character and they can be useful at directing the activity in future.

Although they have in view an operational approach of the main productive consumption through consumption laws, this aspect is limited to the quantitative part and it usually takes place especially for statistical reporting and data gathering for the programming period of the future activity and not for informing the staff involved in taking decisions. This approach is incomplete as, on the one hand, it does not constitute one of the staff's concern and, on the other hand, the information obtained are not rendered in figures, in terms on money, only from quantitative point of view.

Thus, another drawback of this classical method, consequently of the global method used for determining cost, consists in the impossibility of assuring an efficient and systematic control on exploiting expenses found in costs. The activity of gathering and processing such expenses represents the base in establishing the effective cost. Determining cost at the end of the production cycle does not supply information operationally about deviations from the established level which allow decision makers to make proper decisions for setting aside deficiencies.

In order to be able to find deviations from the established level it is necessary to achieve a series of accounting statements, as the accounts system used and the effective way of traditional cost calculation procedure cannot permit finding such deviations. The deviations determined by comparing effective cost with the one that has been established, either economies, or excess levels, are expressed in effective value, without having the possibility to identify the places or the factors that have generated them neither the persons in charge. In order to possibly identify these deviations supplementary calculations have to be done, which involves much work and most times they face the impossibility of providing exact information, even after concluding the productive cycle.

The system of expenses monitoring, adequate to these classical methods, is not able to provide simultaneous supervision of expenses and deviations, their analysis is done most of the times later than necessary and the supplied information cannot be used in the decisionmaking process. They cannot be used for balancing the productive activity while it is being developed, only in subsequent calculations. Neither do they allow each activity department, as a cost centre, to determine clearly and to appreciate objectively the activity results in order to be able to make correct decisions and take proper measures for work improvement for an

\footnotetext{
${ }^{4}$ Calin O., Carstea Gh. (2002), Management accountability and costs calculation, Genicod Publishing House, Bucharest, p.65
} 
optimal fulfilment of the budget objectives, of deviations adjusting and avoiding. It is not about only deviations identified later (that are usually seen too late) but all deviations that can cause a maximum decrease of the information value.

Another limit of the global cost calculation method identified during a study undertaken within one forestry unit is the distribution of indirect expenses to products costs by using conventional criteria, most of the time inadequate, without taking into consideration the cause relationship between expenses to be distributed and the actual base of distribution. As the method is oriented towards the integral unitary cost calculation, it underline especially the production expenses division in direct and indirect expenses and this division do not allow their analysis in relation to production volume. It is a very well-known aspect, from economic point of view, that costs are appreciated in relation to production volume. This aspect involves costs calculation by dividing production expenses into fixed and variable ones, such division being assured only by modern methods of costs calculation.

Consequently, in forestry it becomes compulsory to perfect and diversify the methods of management accountability and costs calculation by introducing some new methods and proceedings able to increase from the qualitative point of view costs information, allowing thus management accountability to fulfil successfully its role.

The effective development of the activity within the forestry unit, as well as its managing draws more and more often the attention to determine beforehand productive consumption levels, costs evolution and to compare them to the level established by the forestry Administration, according to which there are organized wood auctions (for forestry units in the system) as well as to the level reached by private forestry units which have already become a powerful competitor on the market. It also become necessary to supervise efficiently expenses, to know expenses size and their structure, to determine in the shortest possible time the deviations from the established level, the causes that have lead to such deviations and last but not least to identify their exact position.

Management accountability should assure the quick gathering of exact, clear data, adequate to different aspects of the current management activity. The rational use, as well as the sending in time of such information will entitle the forestry unit management staff to react to problems in the shortest possible time, to name the cause and to elaborate a coherent system of measures which will determine sustainable and efficient forests management.

Thus, the necessity of permanent costs reduction for assuring economic efficiency within each forestry unit, as well as the requirements imposed by entities' management in the present market economy, calls for perfect methods of costs calculation. They have in view increasing the role of such methods for founding current and future decisions about the rational using of production factors (the forest seen from economic point of view and its social and ecological functions), perfecting technological processes and adjusting an efficient organizational structure.

It becomes necessary to adopt certain methods, systems and techniques of funding, collecting and distributing production expenses and costs calculations, which can assure promptitude, time saving and simplicity, qualities that in the end determine the improvement of results quality for each forestry unit. Thus, such new systems, methods and techniques used for costs calculation should result out of the analysis of the real present situation within each forestry unit as well as taking into consideration the future requirements necessary for the aimed objectives, so that to perfect the functional position accounting detains in general and management accounting especially within the leadership activity. According to a critical analysis of the present situation, which still offers positive elements, they should promote new methods, capable to supply useful information to the managerial staff, needed when making decisions, capable to allow an adequate valorisation of information related to the production process.

The method that can meet the requirements of scientific management and of the economic activity within the forestry unit is the standard cost one: 
The advantages that can be obtained after having applied the standard-cost method can be noted as follows ${ }^{5}$ :

- It assures an operational control on production costs, as the information supplied, concerning the deviations from the standard costs can be registered at short intervals, so they have an operational and favourable character. The method allows thus making decisions during the production process development and not only after it has been performed;

- It represents an efficient means for performing preventive control on production expenses, by establishing before some standards for the rational use of materials, salaries and other details for each work place;

- By comparing the effective cost with the established one we can identify not only the size of savings, but we can also know in due time the causes and the responsible staff who has caused such deviations. Moreover, the deviations can be analyzed thoroughly, both on cost elements and on price and quantity elements;

$\rightarrow$ The standard costs are pre-calculated production costs on scientific, rigorous base, and they are considered real, normal costs, each deviation related to these being considered a deviation from the normal which will affect the financial results of the unit;

- They cannot offer as an excuse the lack of a pattern that can be used in effective production costs comparison, which can permit us to identify what is normal (by applying the traditional calculation methods the reference elements used for comparing effective expenses could have contained inefficiencies up to an undetermined level), offering the possibility of performing costs control;

$\Rightarrow$ The standard-cost method includes in its working technique adequate systems of production cost concrete processing and of relating a pre-calculated cost deviations, in comparison with the classical methods used for costs calculation which do not include these systems organically, each enterprise having in view their possible organization;

$\Rightarrow$ The standard cost is considered a normal production cost; the calculation of the effective cost is no longer necessary. From mathematical point of view, the effective cost is transformed into a derivative quantity and it will be obtained by calculating the plus or minus of the standard cost and the deviations of the present expenses in comparison to the standard ones. It avoids thus two series of operations (provisional calculation and historical costing) as in the case of traditional calculation methods;

$\rightarrow$ From economic point of view, costs are judged in relation to production size, some being variable and some others stable. Thus, the standard cost method emphasizes costs grouping according to their evolution against the physical volume of production (indirect expenses have a mobile and a stable side), unlike classical methods which are oriented towards grouping production costs in direct and indirect ones;

- It allows grouping costs into stable and variable according to their evolution in comparison to the evolution of the physical size of production, on the one hand, and costs grouping into direct and indirect ones, according to their proportion in the products costs. Deviations are thus determined within the organizational structures, both on calculation item and on other causes, creating analyzing possibilities of the financial results and activity control for each responsibility department;

- It makes possible future costs estimations, as they reflect future objective-costs based on deficiencies elimination and they are preferred against estimations based on adjusting costs registered in the past which could have contained previous deficiencies;

- Standard costs represent an important information source by means of which planned production can be transformed into physical and monetary necessary resources and they help budget planning;

\footnotetext{
${ }^{5}$ Tenovici C.O. (2007) Projecting the informatic system of cost determination and analisys in forestry, Universitaria Publishing House, Craiova, p.23
} 
- Standard costs are set costs, with normative character which allows managerial performances assessment within the company for a given period.

Encouraging modern management methods should take into account the fact that they rely, from the point of view of their characteristics, their structure and their perfection level, on a series of factors, such as: the social and economic system characteristics, an adequate informational system and the staff's level of training and knowledge. Management techniques and methods, from the point of view of their characteristics, have a collective character and a general structure with possibilities of scientific application on different levels of management. Through their content they determine responsibility improvement, allow classifying social and economic phenomena and are based on a scientific language.

Managing a forestry unit involves, on the one hand, a good knowledge of the present activity in order to be able to interfere with operational decisions in its directing and, on the other hand, prefiguring its future evolution and setting up a predictive research which can underline the development principles in perspective. The information determines the managerial staff involvement through decisions which have the role of setting objectives, of organizing, coordinating and directing collective actions for achieving the purpose. The decision represents the essential moment for every managerial process as it involves all managerial functions. By making decisions, the managerial staff chooses the most appropriate way of acting among many possibilities. The decision, as a behaviour form, based on information has been always a means of directing and coordinating economic activities.

Using modern methods and techniques of management provides a higher level of accuracy and confidence. Thus mathematical approaches on economic processes, operational research development and its application, cybernetics and informatics are the most significant progresses that the science offers to any economic management process.

Scientific management involves data automatic processing, using a mathematical apparatus adequate to decisions preparation and applying modern methods of activity control. Through modelling we have in view the logical arrangement of a set of operations or of a process, by using a formalization methodology. A formal model represents, in fact, a simplified, but suggestive, configuration of the reality it represents.

According to some models of operational research we can proceed to a comprehensive analysis of all variables for evaluating the consequences of some different solution given to the problem, offering a simple and real base that helps management in the making decisions process. Thus, operational research becomes a priceless tool in forecasting different variants' consequences, offering the managerial staff the possibility of choosing the most efficient one. Decision, as part of the decisional process, does not represent a purpose itself, but it has to be applied correctly through correct actions and deed, its finality depending directly on the staff's capacity.

Besides decision, economic information represents the second element of the cybernetic concept used in management and economic activities adjustment activities. Therefore, we can speak about the necessity of organizing an informing activity for managerial staff, capable to see promptly what is essential and characteristic in the current activity of the forestry unit. Setting up a modern informational system in forestry units have in view offering solutions to problems so that the informational process to be related to the decisional one. In taking decisions we always start from an existent result and we have in view a desirable one. The need of making a decision appears when the system faces a problem which looks forward to a quick solution. The decision involves, besides the human factor, the unit environment, as we have to take into account any social, political, technological and economic changes, etc. both on national level and international, especially now when we face a strong globalization trend. It also involves increasing the complexity of the decisional activity, increasing thus the number of variables and limit conditions where decisions will be adopted. 


\section{Studies and Scientific Researches - Economic Edition, no. 15, 2010}

\section{References:}

1. Baciu T.A. (2001), Costurile - organizare, planificare, contabilitate, calculatie, control şi analiză, Ed. Dacia, Cluj- Napoca

2. Calin O., Carstea Gh. (2002), Contabilitate de gestiune şi calculația costurilor, Ed. Genicod, Bucureşti

3. Tenovici C.O. (2007), Proiectarea sistemului informatic de calculație si analiză a costului in Silvicultură, Ed. Universitaria, Craiova 